\section{Optimization of distyryl-Bodipy chromophores for efficient panchromatic sensitization in dye sensitized solar cells $\dagger$}

\author{
Safacan Kolemen, ${ }^{a}$ O. Altan Bozdemir, ${ }^{a}$ Yusuf Cakmak, ${ }^{a}$ Gokhan Barin, ${ }^{a}$ Sule Erten-Ela, ${ }^{b}$ \\ Magdalena Marszalek, ${ }^{c}$ Jun-Ho Yum, ${ }^{c}$ Shaik M. Zakeeruddin, ${ }^{c}$ Mohammad K. Nazeeruddin, ${ }^{c}$ Michael Grätzel ${ }^{c}$ \\ and Engin U. Akkaya*ad
}

Received 27th December 2010, Accepted 14th February 2011

DOI: 10.1039/c0sc00649a

Versatility of Bodipy (4,4-difluoro-4-bora-3a,4a-diaza-s-indacene) dyes was further expanded in recent dye-sensitized solar cell applications. Here we report a series of derivatives designed to address earlier problems in Bodipy sensitized solar cells. In the best case example, an overall efficiency of a modest $2.46 \%$ was achieved, but panchromatic nature of the dyes is quite impressive. This is the best reported efficiency in liquid electrolyte solar cells with Bodipy dyes as photosensitizers.

\section{Introduction}

The dye sensitized solar cell (DSSC) concept is a viable alternative to traditional semiconductor based photovoltaic constructs. ${ }^{1}$ Practical potential is also being realized in the form of rapid commercialization. $^{2}$ One of the primary issues, which may benefit from rational design, is the choice of the sensitizer dye. Near IR sensitizability and panchromaticity are important and challenging goals and these can be attained in principle by designing appropriate organic dyes. ${ }^{3}$ We are particularly interested in a class of dyes known as Bodipy dyes. ${ }^{4}$ Bodipy dyes are important fluorophores with a multitude of potential applications. $^{5}$ Recent developments in Bodipy chemistry ${ }^{6}$ allow diverse modification on the core structure. Through these modifications, many characteristics of the parent chromophore can be altered in the desired direction, for example, it is possible to shift absorption wavelength from $500 \mathrm{~nm}$ to $800 \mathrm{~nm}$ with simple chemical transformations. $^{7}$ In addition, strong electron donor and acceptor groups can be placed on the chromophore. Solubility and aggregation characteristics of the dyes can also be modulated as needed. ${ }^{8}$

${ }^{a} U N A M$-Institute of Materials Science and Nanotechnology, Bilkent University, 06800 Ankara, Turkey. E-mail: eua@fen.bilkent.edu.tr; Fax: +90 312-266-4068; Tel: +90 312-290-2450

${ }^{b}$ Institute of Solar Energy, Ege University, Bornova, Izmir, 35100, Turkey ${ }^{c}$ Laboratory of Photonics and Interfaces, Institute of Chemical Sciences and Engineering, Ecole Polytechnique Fédérale de Lausanne (EPFL), Station 6, CH-1015 Lausanne, Switzerland

${ }^{d}$ Department of Chemistry, Bilkent University, 06800 Ankara, Turkey $\uparrow$ Electronic Supplementary Information (ESI) available: Experimental Section; synthetic routes, ${ }^{1} \mathrm{H},{ }^{13} \mathrm{C}$ NMR, and mass spectra of sensitizers (PS-1, PS-2, PS-3, PS-4, PS-5, PS-7); absorption spectra of sensitizers PS-1, PS-2, PS-3, PS-4, PS-5, PS-7 on titania; Cyclic voltammograms of the sensitizers PS-3, PS-4, and PS-5; photophysical parameters for PS-7; device fabrication. See DOI: 10.1039/c0sc00649a/

\section{Design and synthesis}

The first rationally designed example of a Bodipy based sensitizer was reported a few years ago, ${ }^{9}$ followed by a few more recent articles including both liquid electrolyte ${ }^{8}$ and solid state ${ }^{10}$ based DSSCs. It is clear that optimal solar cell performance of a photosensitizer is dependent on a large number of parameters; however, absorption range, anchoring groups and the direction
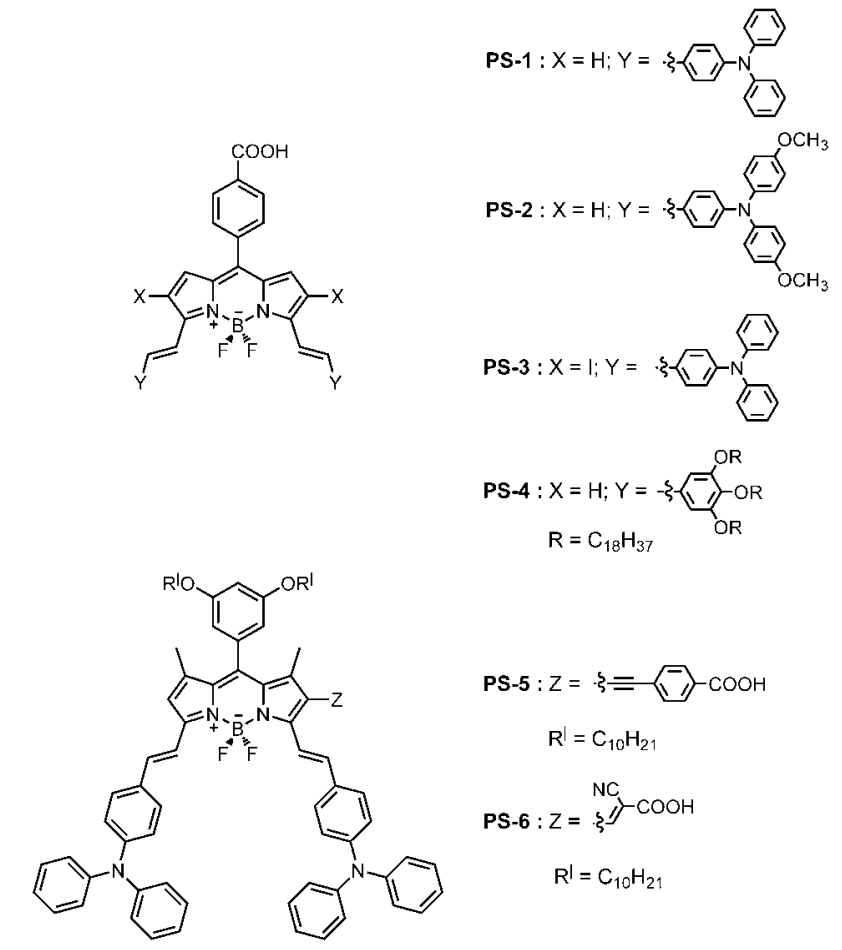

PS-5 : $Z=-\xi=-\mathrm{COOH}$

$\mathrm{R}^{\mathrm{l}}=\mathrm{C}_{10} \mathrm{H}_{21}$

PS-6 : $Z=\stackrel{\mathrm{NC}}{\mathrm{NC}} \mathrm{.} / \mathrm{COOH}$

$\mathrm{R}^{\mathrm{l}}=\mathrm{C}_{10} \mathrm{H}_{21}$

Fig. 1 Sensitizers PS-1 through PS-6. 
of electronic reorganization on excitation should be among the most important ones. Based on earlier $\mathrm{data}^{8 a, 10 a}$ and with the above considerations, we set out to synthesize different Bodipybased photosensitizers for use in liquid electrolyte dye sensitized solar cells (Fig. 1 and Fig. 3). In each one of them, we tried to investigate the role of at least one parameter in solar cell performance. In our first report ${ }^{8 a}$ of a Bodipy based photosensitizer, central chromophoric core was derived from 1,3,5,7-tetramethyl Bodipy. As a result, in that construct the meso-phenyl subsitutent was forced to an orthogonal arrangement in relation
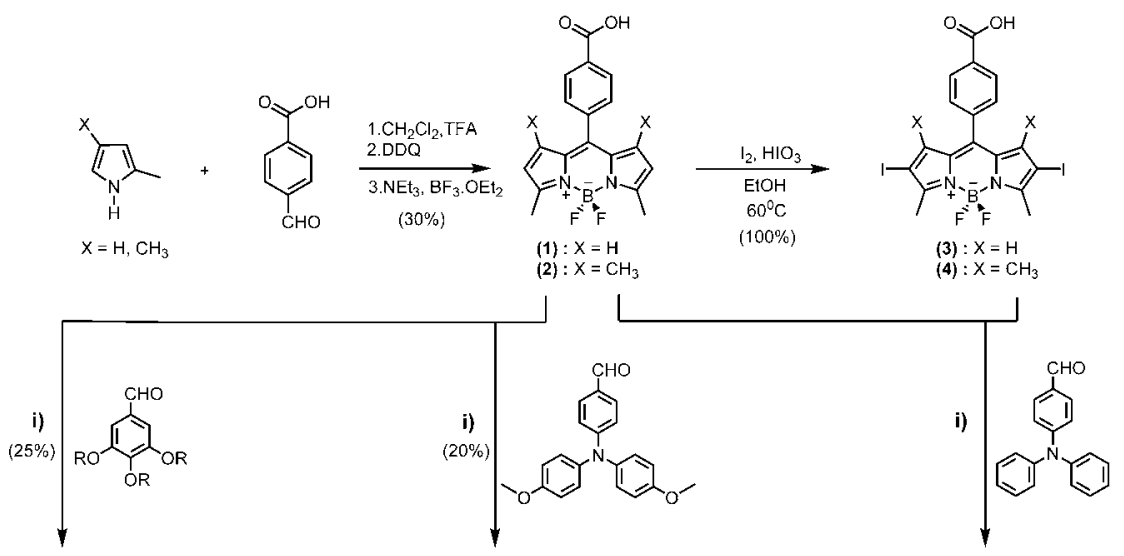

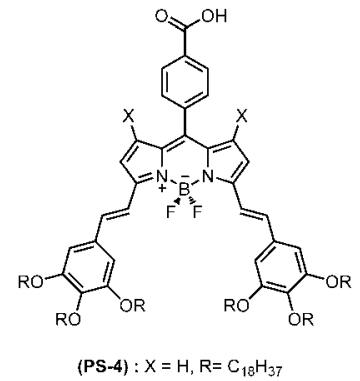

$\mathbf{i}$ = piperidine, $\mathrm{ACOH}$ benzene, reflux $(4 h)$
Dean\&Stark trap

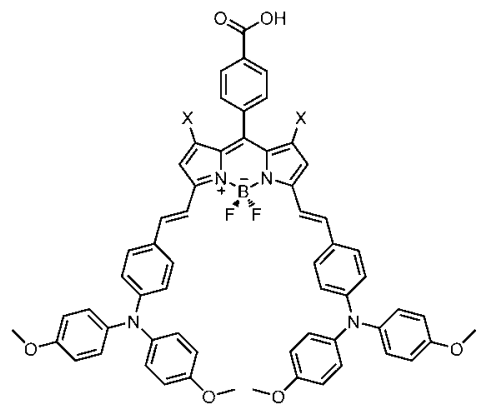

(PS-2) : $X=H$

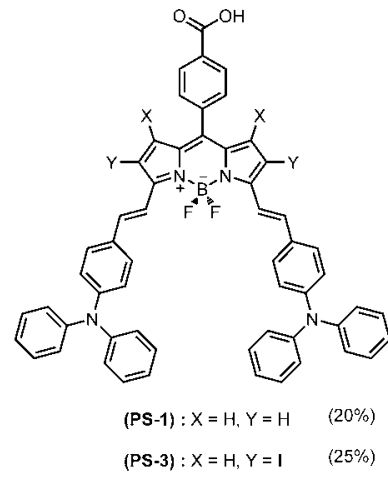

(BOD2) : $X=\mathrm{CH}_{3} Y=1 \quad(35 \%)$

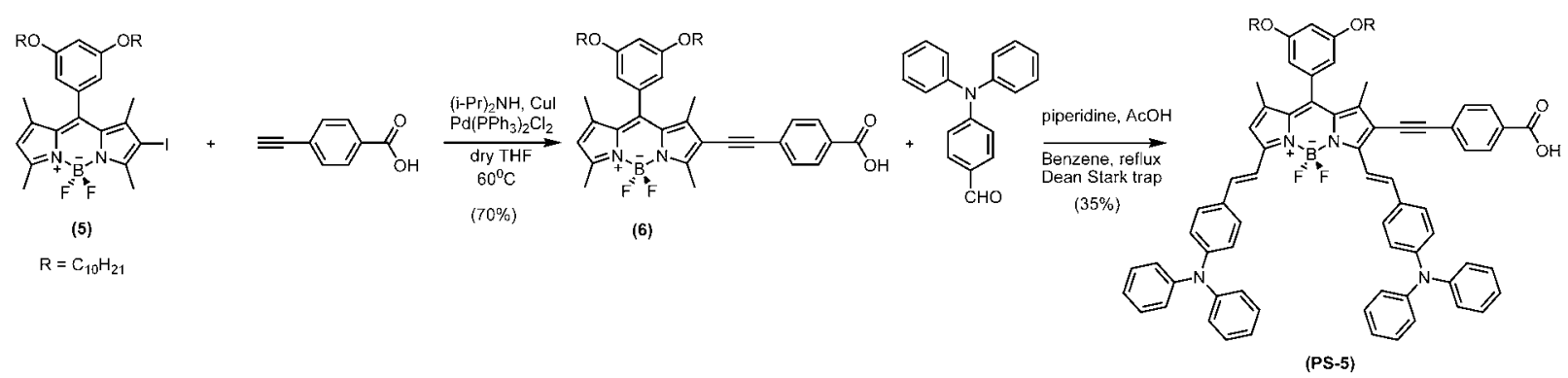

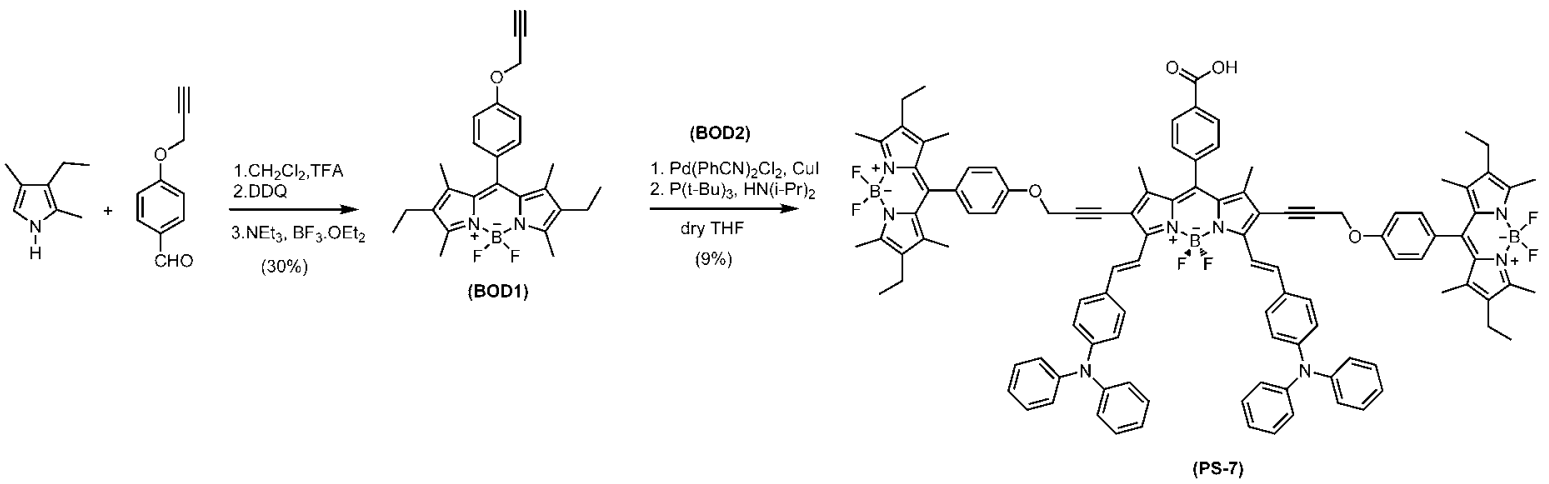

Fig. 2 Reaction scheme for the target sensitizers. 


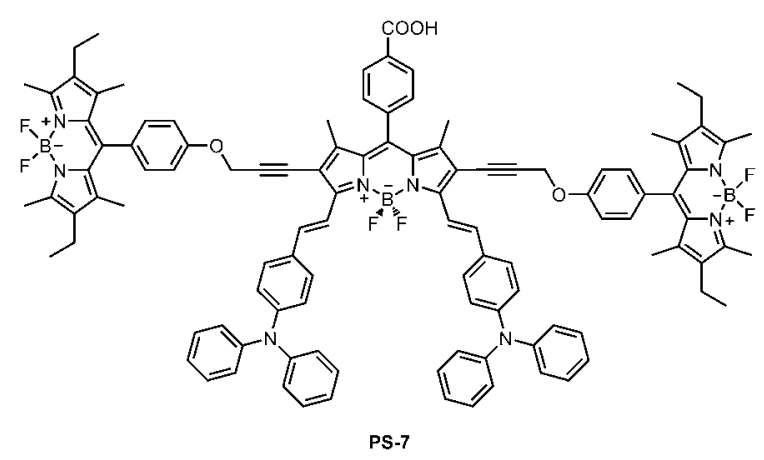

Fig. 3 The molecular structure of the sensitizer PS-7.

to the Bodipy pseudo-plane. The orthogonality of the anchor bearing phenyl group is very likely to limit conjugation and reduce electron flow from the donor to the anchor/acceptor group. With this perspective, it seemed highly reasonable to synthesize a new distyryl Bodipy where two protruding methyl groups at positions 1 and 7 were removed (PS-1).

In the second dye (PS-2), we wanted to study the effect of a stronger donor group on the overall solar cell efficiency. To that end, we replaced diphenylaminophenyl group with bis- $(p$ methoxyphenyl)aminophenyl groups. In designing PS-3, our aim was to find any correlation between the efficiency and the relative ease of populating triplet states. In that compound, placement of two iodo substituents ensure efficient inter system crossing through heavy atom effect related spin-orbit coupling. During the course of this study, we realized that panchromatic absorption, while highly desired, is a consequence of aggregation on titania for the Bodipy derivatives that we studied.

Thus a reasonable goal was to introduce long alkyl chains on the chromophore, either on the donor side or on the mesosubstituent. In PS-4, we replaced diphenylaminophenyl groups with gallic aldehyde derived donor groups. In PS-5, in addition placing these long alkyl groups on the meso substituent, the anchor group is attached directly to the Bodipy core through an ethynyl linkage. PS-6 resembles PS-5 in that aggregation limiting alkyl groups are on the meso substituent and the anchor group is attached directly to the Bodipy core. But here, instead of benzoic acid moiety the anchor group is also a strong acceptor which happens to be a common feature in most photosensitizers for DSSC, ${ }^{11}$ a cyanoacetic acid derived group.

On the other hand, PS-7 (Fig. 3) should be considered separately because with that compound, we wanted to study the effect of excitation energy transfer (mostly through space) in

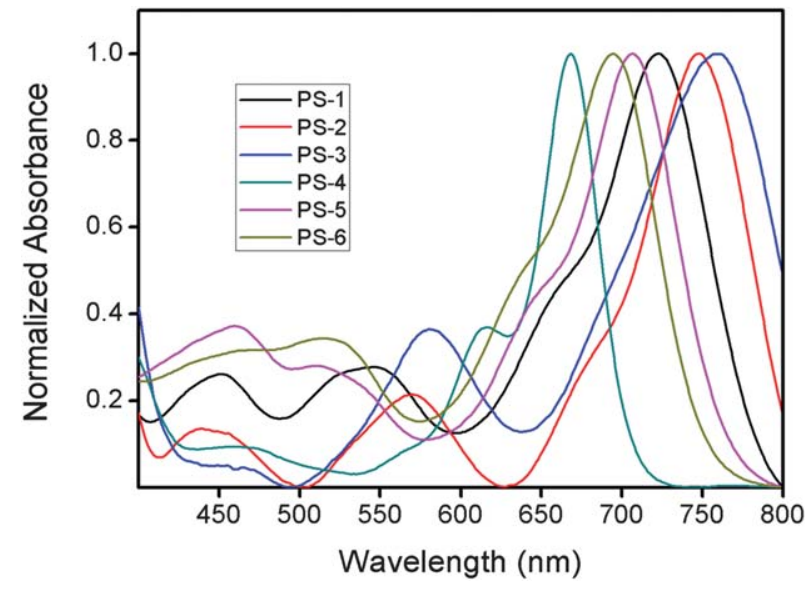

Fig. 4 Normalized absorbance spectra of sensitizers PS-1 through PS-6 in $\mathrm{CHCl}_{3}$.

a photosensitizer. To that end, two Bodipy chromophores were tethered onto the 2 and 6 positions of the core chromophore, which happens to be a longer wavelength absorbing (hence, energy acceptor) distyryl Bodipy dye. Our expectations were; stronger absorption in the entire visible spectrum, enhanced panchromaticity and improved overall photovoltaic yield.

In the synthesis, apart from the well-known Bodipy reaction using the appropriate aldehyde and pyrrole, Knoevenagel and Sonogashira reactions have also been employed (Fig. 2). In PS-3, iodination protocol has been employed with quantitative yield. ${ }^{12}$ The yields are acceptable in all cases, except the final coupling reaction for PS-7. The details of the reactions have been given in the Supporting Information $\uparrow$.

\section{Results and discussion}

\section{Photophysical properties}

In the characterization of the photosensitizers (Table 1), our first goal was to acquire absorption spectra of the sensitizers in solution and on titania and also to demonstrate efficient energy transfer in PS-7. Absorption spectra in solution (Fig. 4) show typical disytryl Bodipy bands $\left(\mathrm{S}_{0} \rightarrow \mathrm{S}_{1}\right)$ in the long wavelength region $(650-760 \mathrm{~nm})$. The absorption peak is somewhat broad, which is not a disadvantage in solar cell applications.

PS-7 shows two distinct absorption bands, one centered around $527 \mathrm{~nm}$ and one $735 \mathrm{~nm}$ (Fig. 5-top). In PS-7, we expect energy transfer from two side chain linked Bodipys to the near IR

Table 1 Optical and electrochemical data of sensitizers PS-1 through PS-6

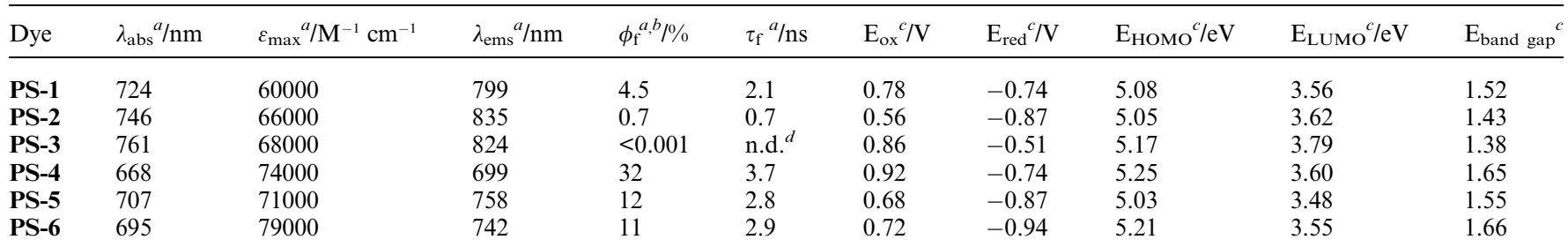

${ }^{a}$ Data were collected in $\mathrm{CHCl}_{3} .{ }^{b}$ PS-4 was determined relative to tetrastyryl dye $\mathbf{1 0}$ and others were to tetrasyryl dye $\mathbf{3}$ according to ref. $7 b$. ${ }^{c}$ Electrochemical data were collected in $\mathrm{CH}_{2} \mathrm{Cl}_{2}$. Potentials were quoted with reference to the internal reference electrode. ${ }^{d}$ not determined. 

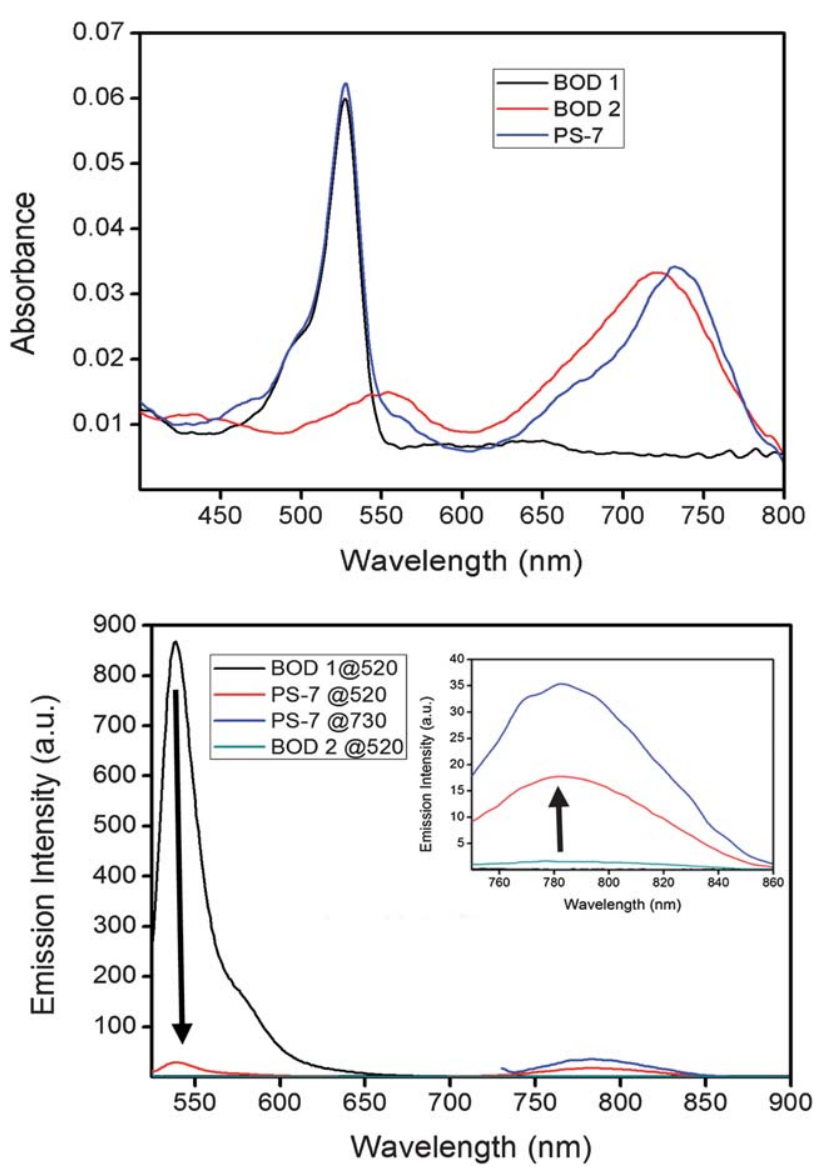

Fig. 5 The absorption spectra of compounds BOD1, BOD2, and PS-7 at equal absorbance values at $527 \mathrm{~nm}$ (for BOD1 and PS-7) and at $725 \mathrm{~nm}$ (BOD2 and PS-7) (top) and emission spectra of the energy transfer cassette (PS-7) in $\mathrm{CHCl}_{3}$ (bottom) in comparison to the selected reference compounds.

absorbing Bodipy core. Model compounds of these two Bodipy units have been synthesized in order to investigate the energy transfer; BOD1 resembles the side chain Bodipy and BOD2 resembles the core unit (Fig. 7). In Fig. 5-top, equal absorbance solutions of the two model compounds and PS-7 were studied, and the efficiency of energy transfer was clearly demonstrated though a comparative depiction of the emission spectra.

Low fluorescence in PS-7 compared to BOD1 at $540 \mathrm{~nm}$ and fluorescence enhancement at $781 \mathrm{~nm}$ compared to BOD2 is a clear confirmation of the energy transfer (Fig. 5-bottom). Quantum yield of BOD1 at $540 \mathrm{~nm}$ is 0.75 , and decreased to 0.05 when employed as an antenna module in PS-7, suggesting a 96\% energy transfer efficiency. Also, the excitation spectrum of PS-7 in Fig. 6 clearly demonstrates energy transfer from the donor to acceptor chromophores, when emission data is collected at 781 $\mathrm{nm}$. Two peaks correspond to the donor $(529 \mathrm{~nm})$ and acceptor $(737 \mathrm{~nm})$ moieties.

\section{Electrochemistry of the sensitizers}

Cyclic voltammetry (CV) results of the Bodipy dyes are given in Table 1. In our previous ${ }^{8 a}$ and present $\mathrm{CV}$ results, Bodipy derivatives showed both reversible reduction and oxidation potentials (Fig. 8). The double oxidation peaks near 0.65 and

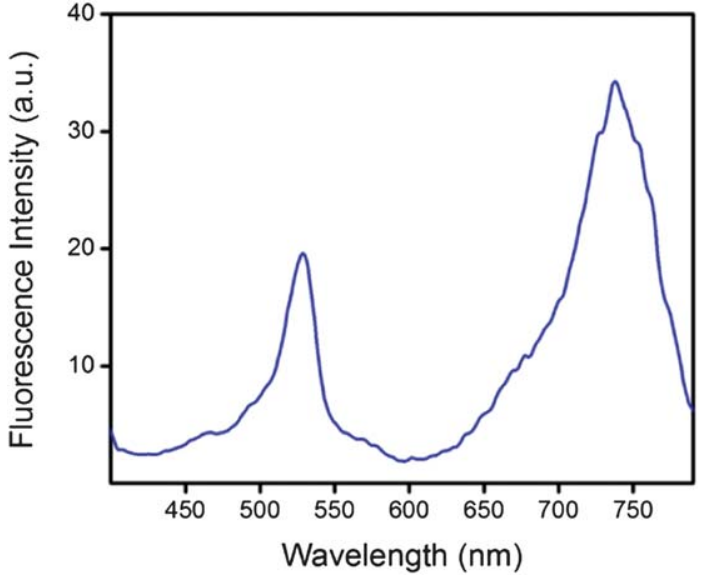

Fig. 6 Excitation spectrum of PS-7. Emission data were collected at 781 $\mathrm{nm}$ with an optically dilute solution in $\mathrm{CHCl}_{3}$.
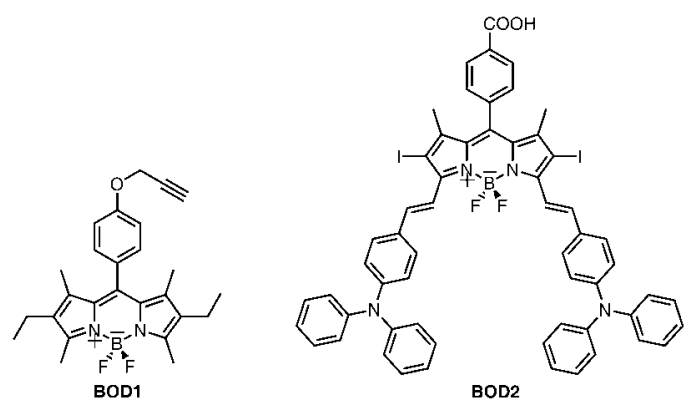

Fig. 7 Structures of model compounds; BOD1 and BOD2.

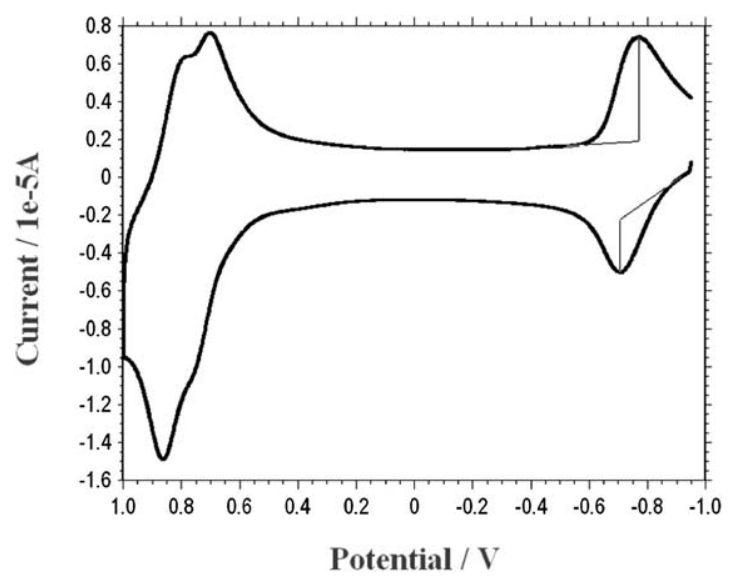

Fig. 8 Cyclic voltammogram of PS-1.

$0.8 \mathrm{~V}$ are likely to be associated with the oxidation of the Bodipy unit and the DPAP (diphenylaminophenyl) moiety, somewhat perturbed $^{13}$ by the electron withdrawing Bodipy core, respectively. It is clear that the LUMO energy levels are appropriate (higher than the conduction band of $\mathrm{TiO}_{2}$ ) for the efficient charge injection from the LUMO level of the sensitizers to the conduction band of the nanocrsytalline titania $(4.2 \mathrm{eV})$. In order to have a continuous electron cycle within the cell, the oxidized dye has to be reduced by the electron donation from the liquid 
electrolyte redox couple $(4.9 \mathrm{eV})$ which is also an energetically favorable process with Bodipy dyes. Charge separation (wide band gap) is strongly needed between the acceptor and donor moieties of the sensitizers for efficient electron transfer. While PS-4 and PS-6 have the wider band gaps, PS-3 has the lowest value. This low charge separation associated with the PS-3 should be considered as one of the reasons for its low overall conversion efficiency.

\section{Photovoltaic characterization}

Typical cell characterization data are presented in Table 2. The IPCE (incident photon to current efficiency) plot as a function of wavelength is essentially flat between the $400-850 \mathrm{~nm}$ region, showing a maximum value (30\%) around $750 \mathrm{~nm}$ (Fig. 9). PS-1 gave an open circuit voltage $\left(V_{\text {oc }}\right)$ of $0.47 \mathrm{~V}$, a short-circuit photocurrent density $\left(J_{\mathrm{sc}}\right)$ of $5.95 \mathrm{~mA} \mathrm{~cm} \mathrm{~cm}^{-2}$, and a fill factor $(f f)$ of 0.67 , corresponding to an overall conversion efficiency $(\eta)$ of $1.88 \%$. Concluding from the data acquired, removal of methyl groups enhances overall efficiency.

Table 2 DSSC performance parameters of Bodipy dyes

\begin{tabular}{lllll}
\hline Dye & $V_{\text {oc }}{ }^{a} / \mathrm{V}$ & $J_{\mathrm{sc}}{ }^{a} / \mathrm{mA} \mathrm{cm}$ & & \\
\hline PS-1 $^{b}$ & 0.47 & 5.95 & 0.67 & $\eta^{a} / \%$ \\
PS-1 $^{c}$ & 0.43 & 9.17 & 0.62 & 1.88 \\
PS-2 $^{b}$ & 0.46 & 4.52 & 0.63 & 1.46 \\
PS-3 $^{b}$ & 0.35 & 1.05 & 0.61 & 0.23 \\
PS-4 $^{b}$ & 0.47 & 5.45 & 0.71 & 1.81 \\
PS-5 $^{b}$ & 0.52 & 3.74 & 0.71 & 1.40 \\
PS-6 $^{b}$ & 0.42 & 2.55 & 0.70 & 0.75 \\
PS-7 $^{b}$ & 0.40 & 0.69 & 0.72 & 0.20
\end{tabular}

${ }^{a} V_{\mathrm{oc}}$ is the open-circuit potential, $J_{\mathrm{sc}}$, short circuit current, $f f$ is the fill factor, and $\eta$ is the overall efficiency of the cell under standard conditions. ${ }^{b}$ Dipping: $4 \mathrm{~h}$ in $0.1 \mathrm{mM}$ THF, $\mathrm{TiO}_{2}: 7+4$, Electrolyte: A6986 [0.6 M 1-butyl-3-methyl imidazolium iodide (BMII), $0.1 \mathrm{M}$ LiI, $0.05 \mathrm{M} \mathrm{I}_{2}, 0.05 \mathrm{M}$ tert-butylpyridine (TBP) in Acetonitrile/Valeronitrile (85/15 v/v)]. ${ }^{c}$ Dipping: $24 \mathrm{~h}$ in $\mathrm{CB} / \mathrm{EtOH}(1: 1)+2 \mathrm{mM}$ cheno (chenodeoxycholic acid), $\mathrm{TiO}_{2}: 8+5+\mathrm{TiCl}_{4}$, Electrolyte: $\mathrm{Z1040}[1 \mathrm{M}$ LiI, $0.044 \mathrm{M} \mathrm{I}_{2}, 0.25 \mathrm{M}$ TBP in Acetonitrile/Valeronitrile (85/15 v/v)].

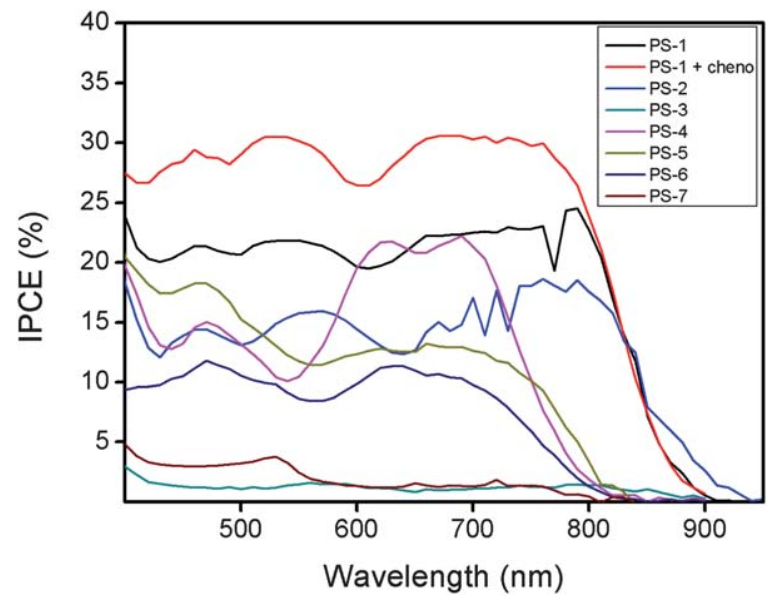

Fig. 9 Incident photon to current conversion efficiencies as a function of wavelength for the liquid electrolyte based DSSCs.

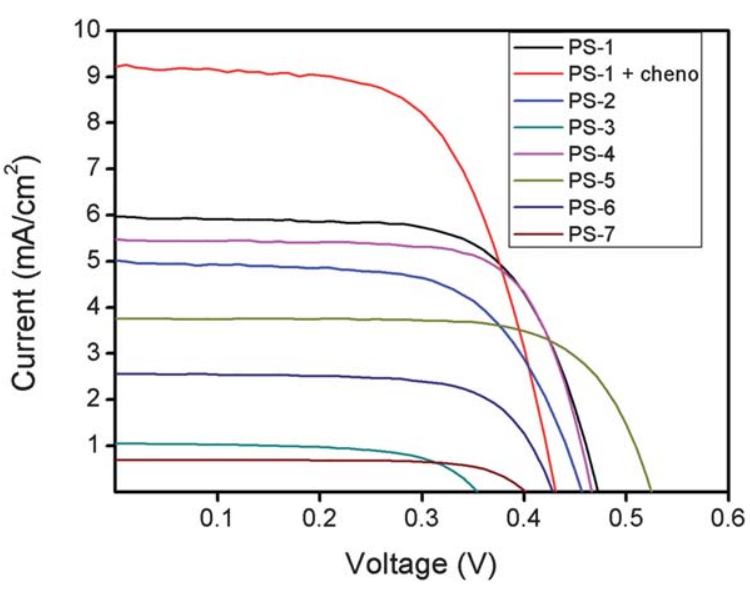

Fig. 10 Current vs. voltage graphs of the photosensitizers.

In PS-2, addition of $p$-methoxy groups on the diphenylamino phenyl moiety seems to provide no positive effect on overall conversion efficiency. Compared to PS-1, PS-2 has a lower short-circuit photocurrent density value. Methoxy substitution just shifted the absorption wavelength and increased the extinction coefficient.

The iodinated Bodipy (PS-3) and the energy transfer cassette sensitizers (PS-7) performed poorly. We suspect easy access to the triplet manifold may open the path to degradative chemical reactions in the diiodo compound and the flexibility of the energy transfer cassette might have led to vibrational losses in energy. PS-3 and PS-7 have the lowest short-circuit photocurrent densities among the sensitizers, which suggests poor electron transfer from the excited dyes to the conduction band of the semiconductor.

Photovoltaic parameters of PS-4 are similar to PS-1. In fact, electron donation from the 3,4,5-tris(octadecyloxy) group is less than the diphenylamino phenyl moiety, suppressed aggregate formation on $\mathrm{TiO}_{2}$ with the help of long alkyl chains gave compatible overall efficiency value.

The orientation of the anchoring groups is also important. Based on our earlier theoretical calculations, ${ }^{8 a}$ it appears that the meso-position (8-position) is better suited for efficient electron injection compared to the 2-position of the Bodipy core. For example, comparing PS-1 and PS-5 would be highly relevant in providing experimental insight into this argument. When the anchoring group is substituted in the meso-position (PS-1), overall conversion is $1.88 \%$. On the other hand, it is $1.40 \%$ for the PS-5 when the anchor group is attached to the 2-position. Further proof for the effectiveness of substitution through the meso-position is the comparison of PS-6 and the Bodipy derivative that we published earlier. ${ }^{8 a}$ Both have a cyanoacetic acid derived group as an anchor, but the positions are different. Overall conversion efficiencies are $0.75 \%$ (2-position substituted) and $1.66 \%$ (meso substituted, $V_{\mathrm{oc}}: 0.56 \mathrm{~V}, J_{\mathrm{sc}}: 4.03 \mathrm{~mA} \mathrm{~cm}{ }^{-2}, f f$ : $0.73)$ respectively.

In our most efficient sensitizer, PS-1, we used chenodeoxycholic acid (cheno) as an additive, which seems to control aggregation and cause an additional boost in the efficiency by improving short circuit current. DSSC with cheno additive gave $9.174 \mathrm{~mA} \mathrm{~cm}^{-2}$ (Fig. 10) short circuit photocurrent density $\left(J_{\mathrm{sc}}\right)$, corresponding to an overall efficiency of $2.46 \%$. This is the best 
reported efficiency in liquid electrolyte solar cells with Bodipy dyes as photosensitizers. Panchromacity remains as impressive as ever. As a matter of fact, the distyryl-Bodipy dyes especially PS1, performs better than most other organic dyes in the near IR region in terms of photon to current conversion efficiency.

\section{Conclusions}

In conclusion, essentially flat curves in the IPCE plot between the wavelengths of 400-800 $\mathrm{nm}$ are highly noteworthy, highlighting the panchromatic nature of these dyes. Bodipy dyes show remarkable properties especially as near IR sensitizers. Modifications for improving the performance of these dyes in other parts of the solar spectrum will make them highly promising as sensitizer dyes for solar cells. Fortunately, it is reasonable to expect the rich chemistry of the Bodipy dyes to yield such derivatives. Our work along this line is in progress.

\section{Acknowledgements}

The authors gratefully acknowledge support from TUBITAK (Grant No. 108T388) and partial support from the Turkish Academy of Sciences (TUBA).

\section{Notes and references}

1 (a) B. O’Regan and M. Grätzel, Nature, 1991, 353, 737; (b) M. Grätzel, Nature, 2001, 414, 338; (c) M. K. Nazeeruddin, Coord. Chem. Rev., 2004, 248, 1161; (d) M. K. Nazeeruddin, A. Kay, I. Rodicio, R. Humphry-Baker, E. Muller, P. Liska, N. Vlachopoulos and M. Grätzel, J. Am. Chem. Soc., 1993, 115, 6382. 2 A. Jager-Waldau, Renewable Sustainable Energy Rev., 2007, 11, 1414. 3 (a) A. Mishra, M. K. R. Fischer and P. Bauerle, Angew. Chem., Int. Ed., 2009, 48, 2474; (b) Y. Ooyama and Y. Harima, Eur. J. Org. Chem., 2009, 2903; (c) N. Robertson, Angew. Chem., Int. Ed., 2008, 47, 1012; (d) S. Ito, H. Miura, S. Uchida, M. Takata, K. Sumioka, P. Liska, P. Comte, P. Pechy and M. Grätzel, Chem. Commun., 2008, 5194; (e) J. He, G. Benko, F. Korodi, T. Polivka, R. Lomoth, B. Akermark, L. Sun, A. Hagfeldt and V. Sundstrom, J. Am. Chem. Soc., 2002, 124, 4922; $(f)$ H. Imahori, T. Umeyama and S. Ito, Acc. Chem. Res., 2009, 42, 1809; (g) N. Koumura, Z.-S. Wang, S. Mori, M. Miyashita, E. Suzuki and K. Hara, J. Am. Chem. Soc., 2006, 128, 14256; $(h)$ A. Ajayaghosh, V. K. Praveen and C. Vijayakumar, Chem. Soc. Rev., 2008, 37, 109; (i) S. Sreejith, P. Carol, P. Chithra and A. Ajayaghosh, J. Mater. Chem., 2008, 18, 264.

4 (a) G. Ulrich, R. Ziessel and A. Harriman, Angew. Chem., Int. Ed., 2008, 47, 1184; (b) R. Ziessel, G. Ulrich and A. Harriman, New J. Chem., 2007, 31, 496; (c) A. Loudet and K. Burgess, Chem. Rev., 2007, 107, 4891 .
5 (a) O. A. Bozdemir, Y. Cakmak, F. Sozmen, T. Ozdemir, A. Siemiarczuk and E. U. Akkaya, Chem.-Eur. J., 2010, 16, 6346; (b) S. Erbas, A. Gorgulu, M. Kocakusakogullari and E. U. Akkaya, Chem. Commun., 2009, 4956; (c) O. A. Bozdemir, R. Guliyev, O. Buyukcakir, S. Selcuk, S. Kolemen, G. Gulseren, T. Nalbantoglu, H. Boyaci and E. U. Akkaya, J. Am. Chem. Soc., 2010, 132, 8029; (d) T. Bura, P. Retailleau and R. Ziessel, Angew. Chem., Int. Ed., 2010, 49, 6659; (e) T. Ozdemir, S. Atilgan, I. Kutuk, L. T. Yildirim, A. Tulek, M. Bayindir and E. U. Akkaya, Org. Lett., 2009, 11, 2105; (f) R. Guliyev, O. Buyukcakir, F. Sozmen and O. A. Bozdemir, Tetrahedron Lett., 2009, 50, 5139; (g) L. L. Li, J. Y. Han, B. Nguyen and K. Burgess, J. Org. Chem., 2008, 73, 1963; (h) J. L. Fan, K. X. Guo, X. J. Peng, J. J. Du, J. Y. Wang, S. G. Sun and H. L. Li, Sens. Actuators, B, 2009, 142, 191; (i) X. Qi, E. J. Jun, L. Xu, S.-J. Kim, J. S. J. Hong, Y. J. Yoon and J. Yoon, J. Org. Chem., 2006, 71, 2881; (j) X. Qi, S. K. Kim, S. J. Han, L. Xu, A. Y. Jee, H. N. Kim, C. Lee, Y. Kim, M. Lee, S.-J. Kim and J. Yoon, Tetrahedron Lett., 2008, 49, 261; (k) S. Ozlem and E. U. Akkaya, J. Am. Chem. Soc., 2009, 11, 48.

6 (a) K. Umezawa, Y. Nakamura, H. Makino, D. Citterio and K. Suzuki, J. Am. Chem. Soc., 2008, 130, 1550; (b) K. Rurack, M. Kollmannsberger and J. Daub, Angew. Chem., Int. Ed., 2001, 40, 385; (c) A. Haefele, C. Zedde, P. Retailleau, G. Ulrich and R. Ziessel, Org. Lett., 2010, 12, 1672; (d) D. C. Wang, J. L. Fan, X. Q. Gao, B. S. Wang, S. G. Sung and X. J. Peng, J. Org. Chem., 2009, 74, 7675.

7 (a) Z. Dost, S. Atilgan and E. U. Akkaya, Tetrahedron, 2006, 62, 8484; (b) O. Buyukcakir, O. A. Bozdemir, S. Kolemen, S. Erbas and E. U. Akkaya, Org. Lett., 2009, 11, 4644; (c) T. Rohand, W. Qin, N. Boens and W. Dehaen, Eur. J. Org. Chem., 2006, 4658.

8 (a) S. Erten-Ela, D. Yilmaz, B. Icli, Y. Dede, S. Icli and E. U. Akkaya, Org. Lett., 2008, 10, 3299; (b) D. Kumaresan, R. P. Thummel, T. Bura, G. Ulrich and R. Ziessel, Chem.-Eur. J., 2009, 15, 6335; (c) C. Y. Lee and J. T. Hupp, Langmuir, 2010, 26, 3760.

9 S. Hattori, K. Ohkubo, Y. Urano, H. Sunahara, T. Nagano, Y. Wada, N. V. Tkachenko, H. Lemmetyinen and S. Fukuzumi, J. Phys. Chem. B, 2005, 109, 15368.

10 (a) S. Kolemen, Y. Cakmak, S. Erten-Ela, Y. Altay, J. Brendel, M. Thelakkat and E. U. Akkaya, Org. Lett., 2010, 12, 3812; (b) T. Rousseau, A. Cravino, T. Bura, G. Ulrich, R. Ziessel and J. Roncali, Chem. Commun., 2009, 1673; (c) T. Rousseau, A. Cravino, T. Bura, G. Ulrich and R. Ziessel, J. Mater. Chem., 2009, 19, 2298; (d) B. Kim, B. Ma, V. R. Donuru, H. Liu and J. M. J. Frèchet, Chem. Commun., 2010, 46, 4148; (e) T. Rousseau, A. Cravino, E. Ripaud, P. Leriche, S. Rihn, A. D. Nicola, R. Ziessel and J. Roncali, Chem. Commun., 2010, 46, 5082.

11 (a) J. R. Durrant, S. A. Haque and E. Palomares, Coord. Chem. Rev., 2004, 248, 1247; (b) G. Benko, J. Kallioinen, J. E. I. KorppiTommola, A. P. Yartsev and V. Sundstrom, J. Am. Chem. Soc., 2002, 124, 489.

12 T. Yogo, Y. Urano, Y. Ishitsuka, F. Maniwa and T. Nagano, J. Am. Chem. Soc., 2005, 127, 12162.

13 D. P. Hagberg, T. Edvinsson, T. Marinado, G. Boschloo, A. Hagfeldt and L. Sun, Chem. Commun., 2006, 2245. 